\title{
Role of clinical pharmacist in rational therapy of pediatric seizures
}

\author{
${ }^{*}$ Chaitanya Lakshmi ${ }^{1}$, Babitha ${ }^{1}$, Ramesh ${ }^{2}$, Dhanapal ${ }^{1}$, Manavalan ${ }^{1}$ \\ ${ }^{1}$ Department of Pharmacy Practice, Annamalai University, Annamalai Nagar \\ 2Department of Pediatrics, Rajah Muthiah Medical College and Hospital, Annamalai University, Annamalai Nagar- \\ 608002, Chidambaram, Tamil Nadu, India
}

\begin{abstract}
Seizures are more common in children than in any other age group, except the elderly. In fact, there are several kinds of seizures that affect only children. Sometimes children outgrow their seizures but many need to be treated for their seizures for their entire life. The main objectives of this study are to study the physician prescribing pattern in pediatric seizures and to educate the patient care taker about the disease and the use of drugs in order to control seizures and improve the quality of life. A non invasive prospective observational study was done with 86 pediatric patients from 01.11.2010 to 30.04.2011. Females were found to be more prone to seizures; prevalence of seizure was more in children aged 1-5 years old. Febrile seizures (46.5\%) are the most commonly observed type of seizure in children followed by tonic - clonic seizures $(21 \%)$ and complex partial seizures $(14 \%)$. The other types of seizures observed are simple partial seizures $(7 \%)$, status epilepticus $(2.3 \%)$ and others $(9.3 \%)$. We observed that Clobazam is the most commonly prescribed drug for prophylaxis of febrile seizures. Phenytoin, Clobazam and Sodium valproate were commonly used drug in children. We infer that monotherapy for seizure is effective choice of treatment.
\end{abstract}

Key Words: Antiepileptic drugs, pediatric antiepileptics, rational use, febrile seizures, Clobazam, prescribing pattern.

\section{INTRODUCTION}

Clinical pharmacy is a health science discipline in which pharmacists provide patient care which promotes health, wellness, and disease prevention that optimizes medication therapy (Walker and Whittlesea, 2008). WHO defines rational use of drug as "Rational use of drugs requires that patients receive medications appropriate to their clinical needs, in doses that meet their own individual requirements for an adequate period of time, and at the lowest cost to them and to their community"(Walker and Whittlesea, 2008). Seizures constitute the commonest neurological problem in children with significant epilepsy having its onset in childhood (Sharma et al., 2009). Febrile seizure (FS) is a convulsive event, exclusively occurring in childhood (Jirsch snd Hirsch, 2007). Although the occurrence of febrile seizures in childhood is quite

\footnotetext{
*Corresponding Author:

Chaitanya Lakshmi, Internship student, Pharm. D (Intern)

Department of Pharmacy, Annamalai University

Annamalai Nagar-608 002, Chidambaram

Tamil Nadu, India

E-mail: chaithu_pharma@yahoo.com

Contact No.: +917845538344
}

common, they can be extremely frightening, emotionally traumatic and anxiety provoking when witnessed by parents (Felveit, 2008). Seizure treatment is more successful when given earlier, and prognosis depends on the cause (Rivello, 2009). The main objective of this research paper is to analyze and assess the physician prescribing pattern and to educate the patient's care taker about the disease and the drugs and to improve the quality of life with rational therapy.

\section{MATERIAL AND METHODS}

For this research, patient data collection form and pediatric prescriptions were used. A prospective observational study has been carried out on the role of the clinical pharmacist in rational therapy in pediatric seizures. This study was done in our institution namely Rajah Muthiah Medical College and Hospital (RMMC and H), Annamalai Nagar, Chidambaram. During the study period 01.11.2010 to $30.04 .2011,86$ patients were selected based on the following inclusion and exclusion criteria: 
Table 1: Age-wise distribution of patients.

\begin{tabular}{lcc}
\hline Age & No. of Cases $(\mathbf{n}=\mathbf{8 6})$ & Percentage $\mathbf{( \% )}$ \\
\hline$<1$ Year & 16 & 16 \\
$1-5$ Years & 52 & 61 \\
$6-12$ Years & 20 & 23 \\
\hline
\end{tabular}

\section{Inclusion Criteria}

Patients included in the study depends on their age from newborn, upto 12 years, patients, who are newly diagnosed with seizures and patients who have an established history of seizures with or without neurological deficit and are already under treatment.

\section{Exclusion Criteria}

Patients excluded from the study based on patients aged above 12 years, those with significant Hepatic and Renal Diseases, patients with co-morbidity diseases and patients who discontinue the treatment.

The patients' case history was collected which includes the details like age, sex, family history, general behaviour, behavioural changes. Detailed history was taken regarding the time and duration of attack, symptoms and factors which may trigger seizures, total no. of seizures occurred, cause of epilepsy, type of seizures and its recurrence. Any neurological deficit in the patient was also recorded. The management of patients past illness, his/her improvement, and present medication history were also recorded. The parents of the patient were interviewed for the Adverse Drug Reaction (ADR). Response to the treatment was assessed and counseled accordingly.

\section{RESULTS}

Out of eighty six cases, $14(16.28 \%)$ were $<1$ year, 52 $(60.47 \%)$ were $1-5$ years and $20(23.25 \%)$ were $6-12$ years age distribution. The seizures were more

Table 2: Types of seizures in children.

\begin{tabular}{lcc}
\hline Type of Seizures & $\begin{array}{c}\text { No. of Patients } \\
(\mathbf{n = 8 6 )}\end{array}$ & $\begin{array}{c}\text { Percentage } \\
\mathbf{( \% )}\end{array}$ \\
\hline Typical febrile seizures & 28 & 32.5 \\
Atypical febrile seizures & 12 & 14 \\
Tonic-clonic seizures & 18 & 21 \\
Complex partial seizures & 12 & 14 \\
Simple partial seizures & 6 & 6.9 \\
Status epilepticus & 2 & 2.3 \\
Others & 8 & 9.3 \\
\hline
\end{tabular}

Table 3: Prescribing pattern of antiepileptic drugs.

\begin{tabular}{lcc}
\hline Choice of Drug & No. of Cases $\mathbf{( n = 8 6 )}$ & Percentage $\mathbf{( \% )}$ \\
\hline First Choice & 50 & 58.1 \\
Second Choice & 28 & 32.5 \\
Alternative & 8 & 9.4 \\
\hline
\end{tabular}

prevalent in children aged 1-5 years (Table 1). Out of 86 patients, $52(60 \%)$ were female and $34(40 \%)$ were male (Figure 2). Febrile seizures were found to be common in children (Table 2). Phenytoin, Clobazam and Sodium valproate were commonly used drug in children (Figure 4). Out of 86 patients, 50(58.1\%) were on first choice of drug, 28 (32.5\%) were on second choice of drug and $8(9.4 \%)$ were on alternative choice of drug (Table 3). Monotherapy (64, 74.42\%) was found to be more common followed by combination therapy $(22,25.58 \%)$ (Table 4$)$.

\section{DISCUSSION}

The results of our study are discussed into two sections named, drug prescribed and prescribing pattern. In our study most of the patients were under the age group of 1 - 5 years followed by the age group of less than 1 year and age group above 6 years. Female patients dominated the study. The study was dominated by the patients having febrile seizures and the patients with status epilepticus were found to be the least. Most of the patients were treated with phenytoin irrespective of the gender and age.

\section{Drugs prescribed}

The commonly prescribed drugs in our study were Phenytoin, Sodium valproate, Phenobarbitone, Diazepam, Clobazam, Clonazepam. These drugs were prescribed alone or in a combination with the other drugs. In our study we found out that Phenytoin was prescribed the most in single drug therapy followed by Clobazam and Sodium valproate. In our study the single drug therapy dominated over the combination therapy.

Table 4: Monotherapy vs. combination therapy.

\begin{tabular}{lcc}
\hline Therapy & No. of Cases (N=86) & Percentage (\%) \\
\hline Monotherapy & 64 & 74.42 \\
Combination therapy & 22 & 25.58 \\
\hline
\end{tabular}




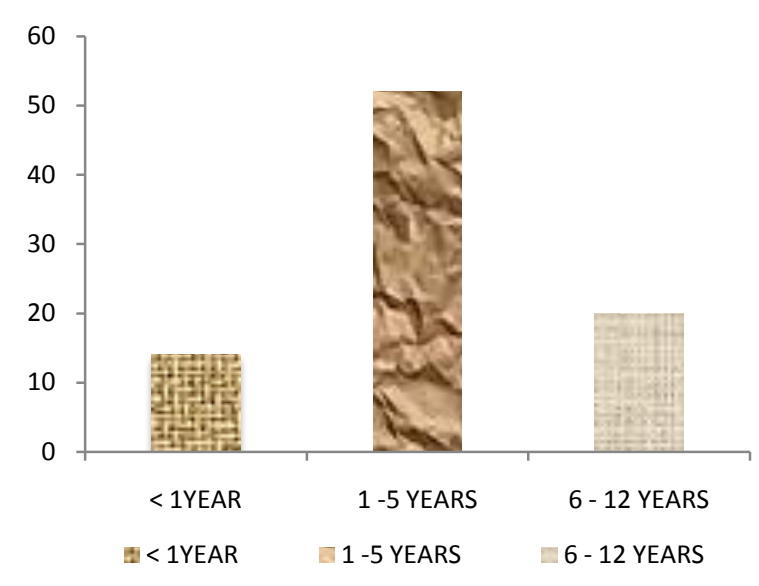

Figure 1: Age-wise distribution of patients.

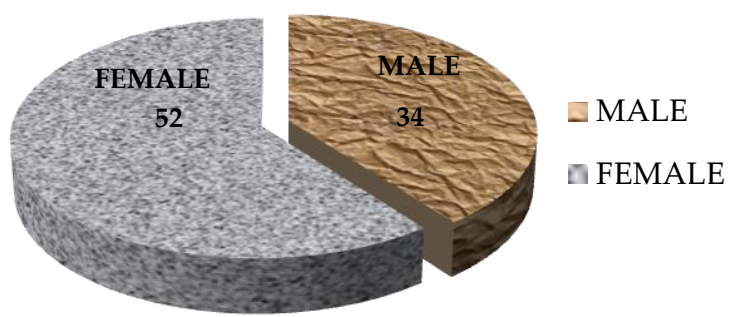

Figure 2: Gender-wise distribution of patients.

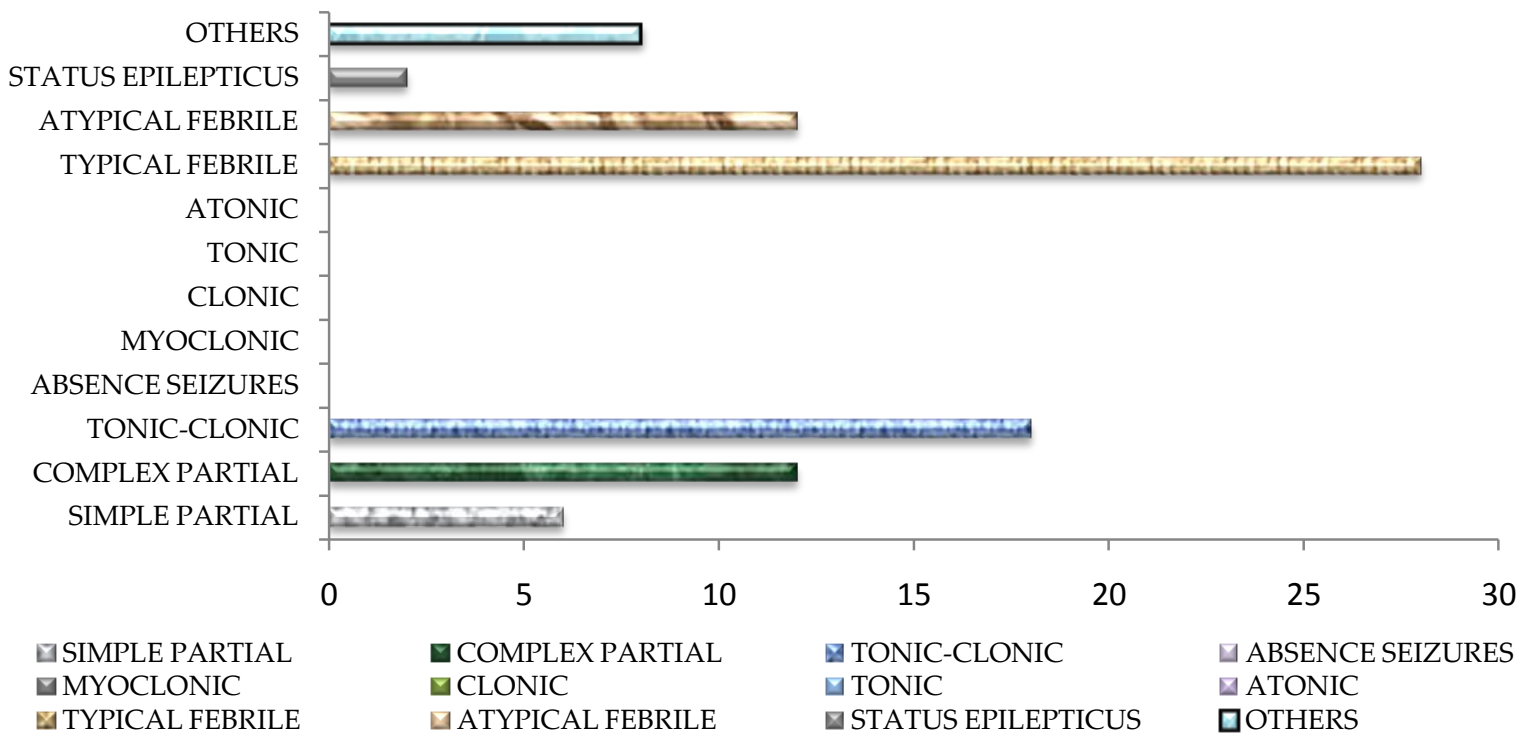

Figure 3: Patient distribution based on the type of seizures.

\section{Prescribing pattern}

Prescribing pattern was equal in prescribing the generics and the branded drugs. Phenytoin was commonly prescribed drug and Clobazam was prescribed for prophylaxis of febrile seizures. Monotherapy dominated the study.

\section{CONCLUSION}

From our prospective observational study, the prescribing pattern of antiepileptic drugs in pediatrics reveals that Phenytoin was the mostly prescribed drug for seizures, as it is supplied free of cost in RMMC and $\mathrm{H}$. We observed that Clobazam was the mostly prescribed drug for prophylaxis of febrile seizures. Girls were more prone to seizures; prevalence of seizure was more in children aged 1-5 years. Febrile seizures were commonly observed type of seizure in children. Monotherapy for seizure was effective choice of treatment which was found to be most commonly prescribed by the pediatricians in RMMC and $\mathrm{H}$.

The patients and patient's care takers response indicated that majority of them reacted positively in response to the advice they received. This provides evidence that clinical pharmacists are able to contribute to a process that influence patient's behaviour towards drug intake and there by capable of promoting quality health care. 


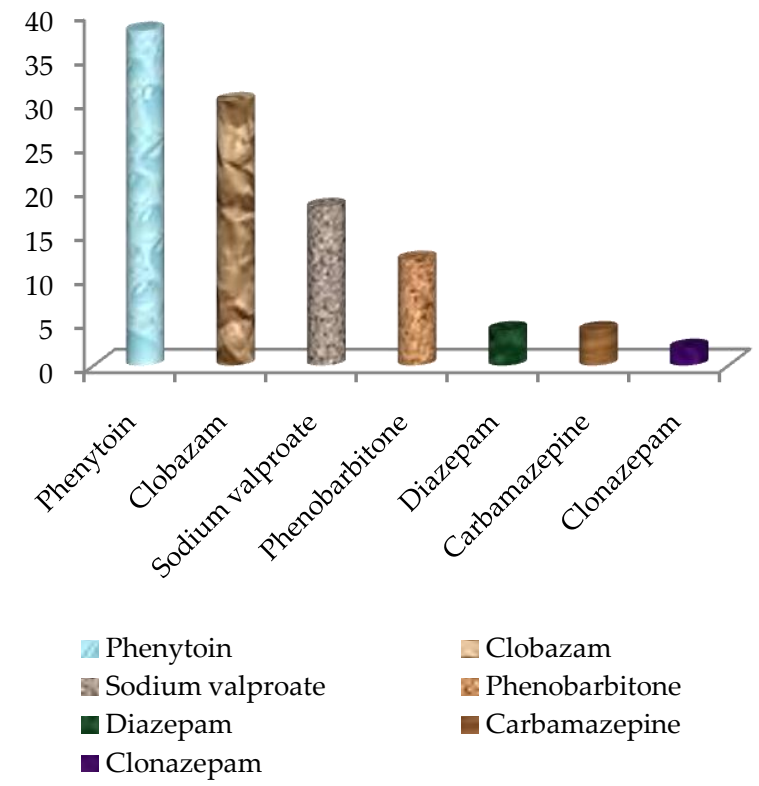

Figure 4: Usage of drugs for the treatment of epilepsy in children.

\section{ACKNOWLEDGEMENT}

We express our profound \& sincere gratitude to Dr. P. K. Manna and Dr. G.P. Mohanta for all the help extended in carrying out the present study. We would like to express our sincere gratitude to all the staff members of Dept. of Pharmacy and Dept. of Pediatrics for providing us guidance and facilities. Words are ineffable to pay our sincere thanks from core of our heart to our friends for all the help, unconditional love and support. We would also like to thank our parents for the support throughout the completion of our study.

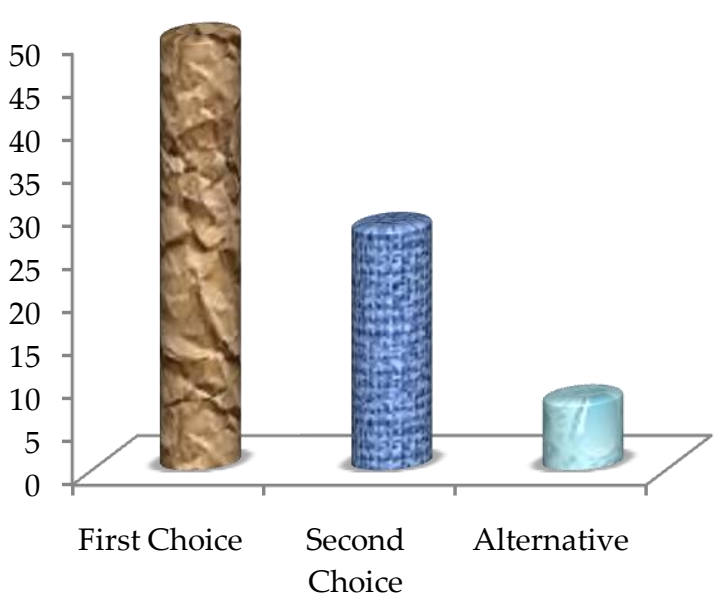

Figure 5: Prescribing pattern of antiepileptic drugs.

\section{REFERENCES}

Anderson, G.D., Lynn, A.M. (2009) Optimizing Pediatric Dosing, Journal of Pharmacotherapy, Volume 29, Issue 6, Pages 680-690. [DOI] PMid:19476420

Beyraghi, N., Hatamian, B., Vesal, A., Tonekaboni, S.H. (2008) Comparison between Diazepam and Phenobarbital in Febrile seizures, Iran Journal of Child Neurology, Volume 2(3), Pages 37-40.

Dipirio, J.T., Wells, B.G., Schwinghammer, T.L. (2009) Pharmacotherapy hand book (7th ed., Pages 1160-1161) McGraw Hill

Felveit, A. (2008) Assessment of febrile seizures in children, European Journal of Pediatrics, volume 167(1), Pages 1727. [DOI] PMid:17768636

Jirsch, J.A., Hirsch, L.J. (2007) Non-convulsive seizures, Journal of Clinical Neurophysiology, volume 118, Issue 8, Pages 1660-1670. [DOI] PMid:17588812

Rivello, J.J. (2009) Seizures in the context of acute illness, Current opinion in Pediatrics, Volume 21, Issue 6, Pages 731-736. [DOI] PMid:19797952

Rocha, G.P., Batista, B.H., Nunes, M.L. (2004) Use of psychoactive and antiepileptic drugs: guidelines for pediatricians, Journal of Pediatrics, Volume 80, Issue 2, Pages: S45-55.

Russell, F.M. (2003) Evidence of use of Paracetamol, Bulletin of World Health Organization, Volume 81, Page 5.

Sharma, S., et al. (2009) Standard Treatment Guidelines- A Manual For Medical Therapeutics (3 ${ }^{\text {rd }}$ ed., Pages 33,36,39) BI Publications Pvt Ltd.

Walker, R., Whittlesea, C. (2008) Clinical pharmacy and therapeutics ( $4^{\text {th }}$ ed., Pages 448,449$)$ Churchill livingstone, McGraw Hill. 